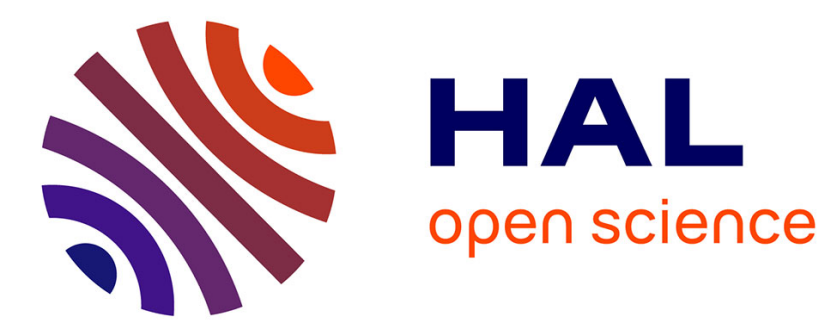

\title{
INTERNAL FRICTION IN DILUTE SOLID SOLUTIONS
}

\author{
P. Feltham, C. Spears
}

\section{To cite this version:}

P. Feltham, C. Spears. INTERNAL FRICTION IN DILUTE SOLID SOLUTIONS. Journal de Physique Colloques, 1985, 46 (C10), pp.C10-223-C10-226. 10.1051/jphyscol:19851050 . jpa00225434

\section{HAL Id: jpa-00225434 https://hal.science/jpa-00225434}

Submitted on 1 Jan 1985

HAL is a multi-disciplinary open access archive for the deposit and dissemination of scientific research documents, whether they are published or not. The documents may come from teaching and research institutions in France or abroad, or from public or private research centers.
L'archive ouverte pluridisciplinaire HAL, est destinée au dépôt et à la diffusion de documents scientifiques de niveau recherche, publiés ou non, émanant des établissements d'enseignement et de recherche français ou étrangers, des laboratoires publics ou privés. 


\title{
INTERNAL FRICTION IN DILUTE SOLID SOLUTIONS
}

\author{
P. FELTHAM AND C.J. SPEARs* \\ Brunel University, Uxbridge, U.K. \\ "The Middlesex Polytechnic, Enfield, U.K.
}

\begin{abstract}
The frequency and amplitude independent internal friction, $Q^{-1}$, of high-purity brasses of $45 \mu \mathrm{m}$ grain size, containing 0.03 to 1.0 at.\% $\mathrm{Zn}$, was studied at $12 \mathrm{kHz}$ at 120 and $290 \mathrm{~K}$. Specimens were prestrained, after annealing, $1.5 \%$ in tension at room temperature before use; at that level of deformation a peak occurred in the strain dependence of $Q^{-1}$ in all cases, suggesting similarity of structures. This peak value was used as the concentration dependent variable. As in the case of concentrated alloys (Phil. Mag.A, 1984, 50, L.35), the loss was ascribed to two interdependent sources: dissipation of line energy, as bowing-out dislocations return quasi-statically to their zero-stress configuration on completion of each half-cycle, and a simultaneous loss of 'elastic' energy by the alloy-atom/dislocation-core configurations. As in the case of concentrated alloys, the relation
\end{abstract}

$$
Q^{-1}=\alpha L^{2}\left[\left(1-\frac{c}{c_{\infty}}\right)^{2}\left(1+\frac{\psi}{8 \Pi \alpha} \frac{c}{c_{\infty}}\right)+\beta\right] /(1+\beta)
$$

accounted well for the observations. Here $\mathrm{N}$ is the density of vibrating dislocations, $L$ the mean spacing between hard pinning-points, $\alpha$ an orientation factor, $B /(1+\beta)$ the fraction of the vibrating dislocations interacting comparatively weakly with alloy atoms (e.g. screws), and $\Psi / 8 \Pi \alpha$ is a constant which, as with concentrated alloys, equals about 0.5 in the amplitudeindependent region; $c_{\infty}$, which depends on $L$, represents the c-level ( $\simeq 1$ at.\% $\mathrm{Zn})$ beyond which $Q^{-1}$ changes comparatively little with zinc content. The observation that $Q^{-1}\left(c, T_{1}\right) / Q^{-1}\left(c, T_{2}\right) \simeq T_{1} / T_{2}$, suggests that $N$ increases approximately linearly with temperature in the range used.

The frequency independent internal friction observed up to well into the $\mathrm{kHz}-$ range in metals 'alloyed' with point defects to low concentrations by irradiation with $\gamma$-rays or MeV-electrons, and also in conventional solid solutions with high solute contents, has recently been interpreted in terms of a model $/ 1,2 /$ in which the elastic potential acquired by the dislocations on bowing-out under the applied cyclic stress is lost to the lattice in the course of the quasi-static return of the pinned arcs from the fully bowed to the zero-stress configurations. The model was developed by reference to individual rather than clusters of pinning points, and could thus be expected to reflect the prevailing modes of point-defect/dislocation interactions in dilute alloys rather more faithfully than in those containing in excess of about 1 at.\% of solute, However, in the former instance its applicability has not, so far, been considered, and the principal object of the present work was to examine its scope in the case of dilute solid solutions. 
Specimens in the form of $12 \mathrm{~cm}$ long rods of $5 \mathrm{~mm}$ diameter were prepared from vacuum-melted $5 \mathrm{~N}$-ingots $(0.03,0.10,0.30,1.0$ at.\% $\mathrm{zn})$; some ingots, of slightly lower purity, alloyed with $0.5,1.0$ and 5.0 at. $\% \mathrm{Zn}$, such as had been studied in earlier work $/ 2-5 /$, were also used, mainly to complement the data, and to check on the continuity of the results with those referred to in connection with the internal friction of $\alpha$-brasses containing up to 30 at. $\% \mathrm{Zn} / 2 /$. The rods were annealed in batches at $760^{\circ} \mathrm{C}$, sealed into close-fitting silica tubes evacuated to about $10^{-5}$ torr. To attain the same grain size $(45 \mu \mathrm{m})$ as in previous work with concentrated brasses, the annealing times were chosen to range from 38 minutes (95/5) and 39 minutes (99/1) to 40 minutes for all specimens with lower zinc contents. The tubes were allowed to cool at room temperature. No dezincification was noted by optical microscopy of sections.

In a preliminary study of the influence of tensile prestrains, induced at room temperature, on the damping, the latter was found to attain a maximum at strains close to $1.5 \%$, as had been observed earlier with the more concentrated solid solutions /3,5/ as well. This 'peak' value was about an order of magnitude higher than the loss in the corresponding, undeformed, specimens, and must thus be ascribed primarily to straininduced, 'un-aged' dislocations. The prestraining was, in fact, carried out immediately before the measurement of the internal friction, i.e. to minimise any ageing effects. All values of $Q^{-1}$ given here refer to specimens deformed in this manner. They were excited into longitudinal vibrations electrostatically at about $12 \mathrm{kHz}$; the amplitude of the cyclic strain was approximately $2.10^{-7}$, i.e. well within the amplitude-independent region.

The results obtained are shown in figure 1; the points denoted by open circles refer to the purer specimens, the full ones to those of lower purity. Each point represents the average of six readings. For the highest $Q^{-1}$-values the instrumental error was comparatively high, a consequence of the rapid decay of the oscillations. The full line drawn through the points for $290 \mathrm{~K}$ was obtained from the relation

$$
Q^{-1}=\alpha N L^{2}\left[\left(1-\frac{c}{c_{\infty}}\right)^{2}\left(1+\frac{\Psi}{8 \pi \alpha} \frac{c}{c_{\infty}}\right)+\beta\right] /(1+\beta)
$$

derived in $/ 1 /$, and recently considered also with reference to concentrated $\alpha-b r a s s e s$ /2/. Here $\mathrm{N}$ is the density of oscillating dislocations after the plastic pre-strain of $1.5 \%$, I the mean spacing between hard pinning points, and $\alpha$ an orientation factor which, as in $/ 1 /$, we estimate to be of the order of $0 \cdot 01 ; \beta /(1+\beta)$ is the fraction of vibrating dislocations not significantly pinned (e'g. screws), $\Psi / 8 \Pi \alpha$ a constant which, as in $/ 2 /$, we shall take equal to $1 / 2$, and $c_{\infty}$ represents the concentration of the alloying element (here 1 at. $\% \mathrm{Zn}$ ) beyond which $Q^{-1}$ becomes substantially less composition dependent than for lower concentrations. It was found to be given $/ 1 /$, in the usual notation, by

$$
c_{\infty}=1 / 2 \mathrm{~Gb}^{3}(\mathrm{~b} / \mathrm{L})^{2}\left(8 / \mathrm{U}_{0}\right) \text {, }
$$

where $U_{0}$ represents the 'elastic' energy stored in the lattice for a local displacement of a dislocation through $b$ from its equilibrium position at an individual, fixed, point defect or allov atom located at the point of maximum binding in the core. With $c=0.01$, also taking $\mathrm{L}=1 \mu \mathrm{m}$, a rough estimate yields here $U_{0}=1 / 4 \mathrm{meV}$. The limited flexibility of the dislocations would be expected to result in an appreciably lower $U_{0}$-value in concentrated solid solutions; this, expected, trend finds support in $/ 2 /$. Values of the remaining parameters used in deriving the upper curve in figure 1 were: $\mathrm{NL}^{2} /(1+\beta)=5 \cdot 10^{-3}$ and, as for concentrated alloys $/ 2 /, \beta=0 \cdot 18$.

As, under certain conditions, clusters of alloy atoms may also act as hard pinning-points, i.e. in addition to the network nodes, jogs, etc., which have been assumed to determine the magnitude of $Q_{0}^{-1}\left(=\alpha N L^{2}\right)$ in eq. (1), L may depend not only on the level of the prestrain, but also, somewhat, on c; such a possible c-dependence of the spacing $L$ was not allowed for in the present considerations, appertaining to relatively dilute alloys. 


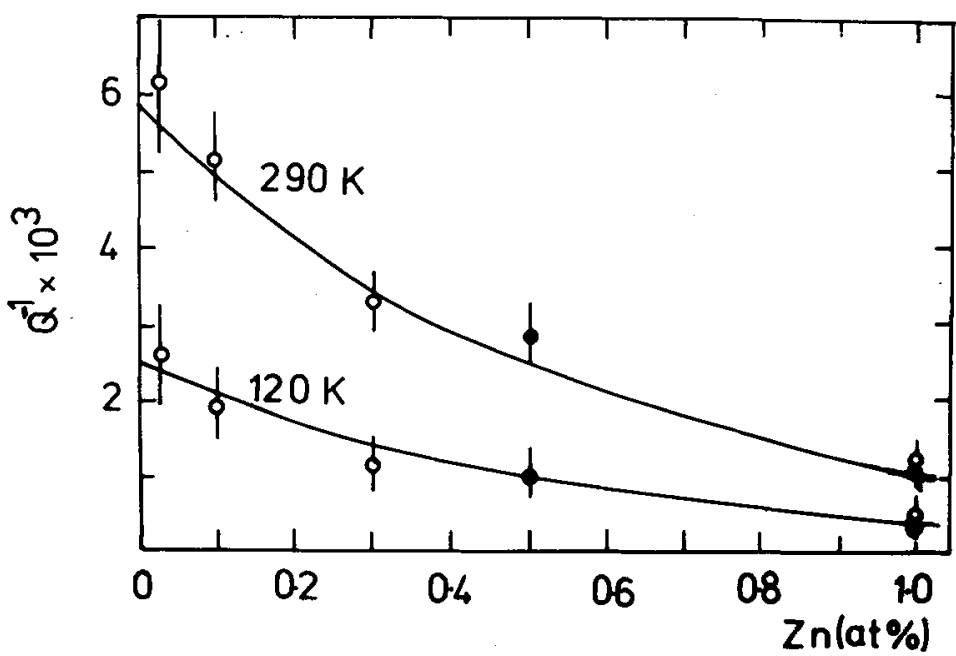

Fig. 1 - The internal friction of polycrystalline $\alpha$-brasses prestrained $1.5 \%$ in tension at room temperature. Data points for specimens of high purity are denoted by open circles; full ones refer to'specimens of lesser purity. The curve for $290 \mathrm{~K}$ was obtained by means of eq.(1) with parameters given in the text; that for $120 \mathrm{~K}$ was derived from the former by scaling down as indicated by eq. (3).

The curve in the figure relating to $120 \mathrm{~K}$ was obtained from that for $290 \mathrm{~K}$ by scaling, i.e.

$$
Q^{-1}(c, 120) / Q^{-1}(c, 290)=120 / 290 \text {. }
$$

An almost linear temperature dependence of the magnitude of the internal friction peak, consistent with eq. (3), was also found with concentrated $\alpha$-brasses in the range $120-300 \mathrm{~K} / 2 /$. The linear scaling implies that the functional form of eq. (1) is the same for both temperatures, so that $c_{\infty}$, and hence also $\mathrm{L}$ (eq.2), would be expected to remain nearly temperature invariant, at least over the range $120-290 \mathrm{~K}$. The increase of $Q^{-1}$ with temperature then appears to be largely a consequence of an increase in $Q_{0}^{-1}$ and, more specifically, in the density, $N$, of vibrating dislocations. A parallel observation, of the effect of temperature on $Q^{-1}$ in the case of concentrated $\alpha$-brasses led previously $/ 2 /$ to the same surmise.

In annealed $5 \mathrm{~N}$-copper single crystals, as well as in annealed polycrystals of the same material, and also in some of slightly lower purity, the internal friction at amplitudes and frequencies similar to those used in the present work $/ 6 /$ was also found to increase in a monotone, almost linear, manner with increasing temperature $(120-250 \mathrm{~K})$, suggesting that an increasing number of segments, latent at one temperature, contribute to $Q^{-1}$ at a higher one.

The correlation of the data in figure 1 by means of eq.(1) can be seen to be satisfactory, particularly if account is taken of the relative simplicity of the model used.

The authors are most grateful to Professor K. Lücke and Dr. D. Lenz for the gift of the high-purity brass ingots, and to Mr. P. Hicks for the design and construction of the automatic Q-meter used in the present work. 


\section{REFERENCES}

/1/ Feltham, P., Phil. Mag. A, 49 (1984) 727.

12/ Feltham, P., Phil. Mag. A, $\overline{50}$ (1984) L35.

/3/ Spears, C.J. and Feltham, P., J. Mater. Sci., 7 (1972) 969.

/4/ Spears, C.J., J. de Phys., 42 (1981) C5-277.

15/ Spears, C.J., Int. Frict. and Ultras. Attn. in Cryst. Solids. Ed.: D. Lenz and K. Lücke. Springer, Berlin (1975) p.363.

/6/ Feltham, P. and Burdett, C., Struktur and Eigensch. von Reinststoffen.

Ed.: J. Kunze et al. Akademie Verlag, Berlin (1967) p.615. 